\title{
Does family mealtime have a protective effect on obesity and good eating habits in young people? A 2000-2016 review
}

\author{
Abykeyla Mellisse Tosatti 1 \\ Letícia W. Ribeiro 2 \\ Rachel Helena Vieira Machado 3 \\ Priscila Maximino 4 \\ Ana Beatriz Bozzini 5 \\ Cláudia de Cássia Ramos 6 \\ Mauro Fisberg 7

\footnotetext{
1-6 Instituto PENSI. Fundação José Luiz Egydio Setúbal. Av. Angélica, 1968 cj 71. Higienópolis. São Paulo, SP, Brasil. CEP: 01.228-200. E-mail: rhvmachado@gmail.com

7 Departamento de Pediatria. Universidade Federal de São Paulo. São Paulo, SP, Brasil.
}

\begin{abstract}
Objectives: to review the prevalence of family meals and its impact on BMI and eating habits during childhood and adolescence.

Methods: reviews are from Bireme / Lilacs / Scielo / Cochrane and Pubmed, between 2000-2016 with descriptors "family meal or mealtime", "behavior", "nutrition or diet or consumption or eating", and "child or children or adolescence"; performed by two independent examiners, according to the systematic steps in English and Portuguese. The articles were selected based on prevalence and/ or discussion between nutritional variables. 2,319 articles were found, which 15 were selected all in English: systematic reviews $(n=2)$, crosssectional studies $(n=8)$, longitudinal studies $(n=8)$; all related to children $(n=5)$, adolescents $(n=6)$ and both $(n=5)$.

Results: the mean of shared meals was 1x/day, with a prevalence of 27 to $81 \%$. Most studies $(n=13)$ reported the beneficial impact on BMI, higher consumption of fruit and vegetables, protein, calcium and a lower consumption of sweets and sugar sweetened beverages, family union and self-regulation of appetite.

Conclusions: having daily family mealtime has beneficial effect on the nutritional status and children and adolescents' eating behavior.
\end{abstract}

Key words Meals, Child, Adolescent, Nutrition, Eating behavior 


\section{Introduction}

Eating preferences and behaviors are strongly conditioned by the family environment especially when it is the child's first contact in socializing, where eating behaviors are learned and incorporated. Such behaviors, whether it is healthy or not, may persist during adolescence and into adulthood. ${ }^{1,2}$ In this context, family mealtime (described in most studies as the act of eating simultaneously with family members) has been currently recognized as healthy eating habits. ${ }^{3}$

Recent studies show that family mealtime contributes to a higher consumption of healthy food and protects against the development of inappropriate eating habits among children and adolescents, ${ }^{4-6}$ stimulating a greater availability of fruit and vegetables (FV) intake and less consumption of sweets and sugar-sweetened beverages.7 There is also evidence of its impact on reducing obesity: studies with children who received intervention related to the promotion of healthy family mealtime along with responable parents or guardians, presented a reduction in excess weight at the end of the follow-up; 4,8 in addition to the associations of reduced activities and the time spent in front of television. ${ }^{8}$ Another important role is family mealtime to protect against psychosocial disorders, common in certain stages at childhood and especially in adolescence: the association between the habit to have family mealtime and lower occurrence of eating disorders, alcohol and drug use, depressive symptoms and risk factors for suicide between adolescents is emphasized in different studies. ${ }^{3}$

Despite these described benefits in international literature, a low prevalence of family mealtime in households with children is frequently documented. For example, American population data analysis 6 show a prevalence of only $49 \%$ of one daily family mealtime. The current contemporary routine favors habits that contradict family mealtime with more and faster ready-made meals. 5,9

In Brazil, however, the data prevalence on family mealtime, studies in association to children and adolescents' nutritional and behavioral characteristics and intervention studies in this context are scarce. This present study tends to review this practice on the Body Mass Index (BMI) and eating habits at childhood and adolescence, as a preliminary step to the development of a study project on the prevalence and intervention in Brazilian families.

\section{Methods}

This study is a review from BVS literature (Bireme / Lilacs / Scielo / Cochrane) and Pubmed, from 2000 to 2016. The search terms were used in association, according to Boolean operators 'and', 'or': "family meal or mealtime", "behavior", "nutrition or diet, or consumption or eating", "child, childhood or children or adolescence".

The inclusion criteria consisted of selection of studies that aimed in presenting prevalence of habits of family mealtime and/or discussing the relation between this practice and children / adolescent's development, under nutritional and behavioral aspects (at a eating point of view). Only crosssectional or cohort studies or systematic reviews, carried out in Brazil or abroad (only in Portuguese, English or Spanish languages), with children and / or adolescents and of any sample size were included and selected. Articles with complete access that were unavailable were also excluded from the analysis. The selection process of the studies was performed by two independent examiners and according to the following steps occurred: 1) Read titles and summaries from articles found; 2) Exclusion of the articles that did not meet the selection criteria and duplicates; 3) Exclusion of incompatible research focus with the objectives and 4) Read articles completely for final selection. After this process, the articles selected by each examiner were crossed one last time for the exclusion of new duplicates and to conclude the selection of articles.

From 2,319 articles found (541 from BVS and 1,778 from Pubmed), 15 studies were selected and all of them in English, characterized by according to design and populational group: systematic reviews $(n=2)$, cross-sectional studies $(n=8)$, longitudinal studies $(n=8)$. In relation to age, there were studies found that included children $(n=4)$, adolescents $(n=6)$ and both $(n=5)$. The selection process of the articles is described in Figure 1.

\section{Results}

The results regarding the prevalence of frequency in sharing meals are described in Table 1. Among the reviewed studies, the mean of sharing was one daily meal, 10-15 and the prevalence of sharing daily meals ranged from 27 to $81 \% .3,11,12,13,14,15,16,17$ The association between family meals and the BMI and eating habits are described separately below. 
Figure 1

Flowchart on selected articles. PENSE Institute: 2016.

Initial search ofh key words

BVS $=541$

Pubmed $=1778$



Exclusion of duplicates, year of publication

$N=1602$

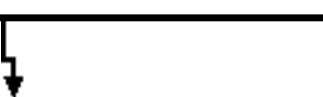

Exclusion of languages out of inclusion criteria

$N=1156$

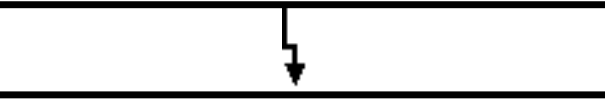

Exclusion of study designs and subjects' age incompatible with inclusion criteria

$\mathrm{N}=910$

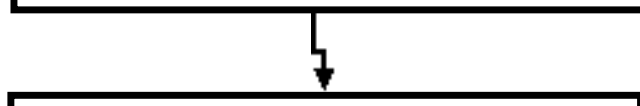

Exclusion of research focus incompatible with the objectives of the study

$$
N=54
$$






\section{Impact on the BMI}

Three studies included in this study assessed the association between BMI and family meals. McCurdy et al.18 in a sample of 164 American school children and of low income, which found that one third of the children were overweight $(17.1 \%)$ or obese (15.9\%) and described an inverse proportion in relation between both. The maternal presence during meals was associated with low values of BMI $(\beta=0.166, p<0.05)$, as well as the best financial resource management and the greater offer on balanced meals by the family $(\mathrm{OR}=0.72-0.95$, $p<0.01)$. Boles et al. ${ }^{19}$ assessed eating practices and parental styles in 52 obese adolescents, persistent and concluded that these young people have significantly more problems with eating practices and less family interactions during meals, especially those with difficult tempers, which suggests an impact in family interactions on BMI. Although, Kong et al. 20 did not find strong association between family meals and low risk on overweight. About $44 \%$ of the children from the sample were at risk of being overweight, and the mean of sharing family meals was once daily. Authors relate the lack of correlation to the small sample size ( $\mathrm{n}=30$ Hispanic, African and non-Hispanic Caucasian families with low-income), and emphasize that ethnic / racial differences may also moderate this relation.

\section{Impact on the food quality}

Five studies included in this study addressed different topics related to food quality and the presence of the family at mealtime. Christian et al. 7 assessed the consumption of fruit, and vegetables (FV) of 2,383 British children enrolled in primary schools - reported a mean of $293 \mathrm{~g} \mathrm{FV/day} \mathrm{intake}$ from which children's families reported "always" eating a daily meal with the family and had $125 \mathrm{~g}$ more of FV intake than families who reported never eating together. The daily FV intake by the parents was associated to a higher intake of FV (88g, CI95\% $=37-138)$ in children, compared to parents who rarely / never consumed FV. Cutting fruit and vegetables for the children was also associated to a greater intake of FV $(44 \mathrm{~g}, \mathrm{CI} 95 \%=18-71)$ in this study.

Wit et al. ${ }^{21}$ also found a better self-regulation of appetite and healthier eating habits among adolescents aged 10 to 17 -year-olds who have family meals more frequently, thus, the mean of sharing in general was two daily meals (breakfast and dinner) for at least 3 days during the week. Larson's et al.,12 study found that adolescents who shared meals more frequently continue to consume more FV and dairy products until 10 years after the initial assessment. Similarly, Burgess-Champoux et al.,17 described higher prevalence of shared meals associated the double intakes of vegetables and nutrients, as well as a $50 \%$ reduction in the consumption of fast food, contributing to promotion healthy eating habits up to five years later.

Flattum et al. 8 developed a program called Healthy Home Offerings via the Mealtime Environment (HOME Plus), to prevent obesity, applied in 81 American families (children aged 8 to 12 years old and their parents) in a ten $2 \mathrm{~h}$-sessions, and five motivational phone calls to promote healthy eating habits and to increase family mealtime. After the interventions of HOME program, $87 \%$ of the parents reported that their children were more receptive in trying new food, $52 \%$ of the children ate more $\mathrm{FV}$, and $86 \%$ of the parents reported that their children were more aware of the portion sizes. Additionally, parents and children have reported that cooking with family members is a pleasant experience, which facilitates the learning of eating healthier.

\section{Discussion}

Among the studies included in this review, thirteen demonstrated beneficial effects of family mealtime in preventing behavioral and nutritional changes in children and adolescents. According to these studies, a family mealtime surpasses the field of sensory experiences with food and in favor of a normal BMI and healthy eating habits (greater intake of FV, proteins, sources of calcium and lower consumption of sweets and sugar-sweetened beverages), family bonding and self-regulation of the appetite. $8,21,18,7,20,19,12,17$

\section{Frequency of family mealtime}

In the present study, a family mealtime occurred, in a mean, once a day, with a wide variety in the prevalence of sharing (27 to $81 \%) .3,16,10,11,12,14,13,17,15$ In comparison to the Brazilian data, Pesquisa Nacional de Saúde do Escolar - PeNSE in 201222 (National Research on School Health) showed that $66.4 \%$ of the students had one daily meal with their families. The highest prevalence $(71.1 \%)$ was reported in the South Region in Brazil, while the lowest was in the Southeast Region (64.6\%). In relation to the cities, Florianópolis had the highest prevalence of family meals (71.5\%); while Salvador was described as the lowest (47\%). Additionally, a study data with 439 mothers in São Paulo State 23 reported an $83.6 \%$ 


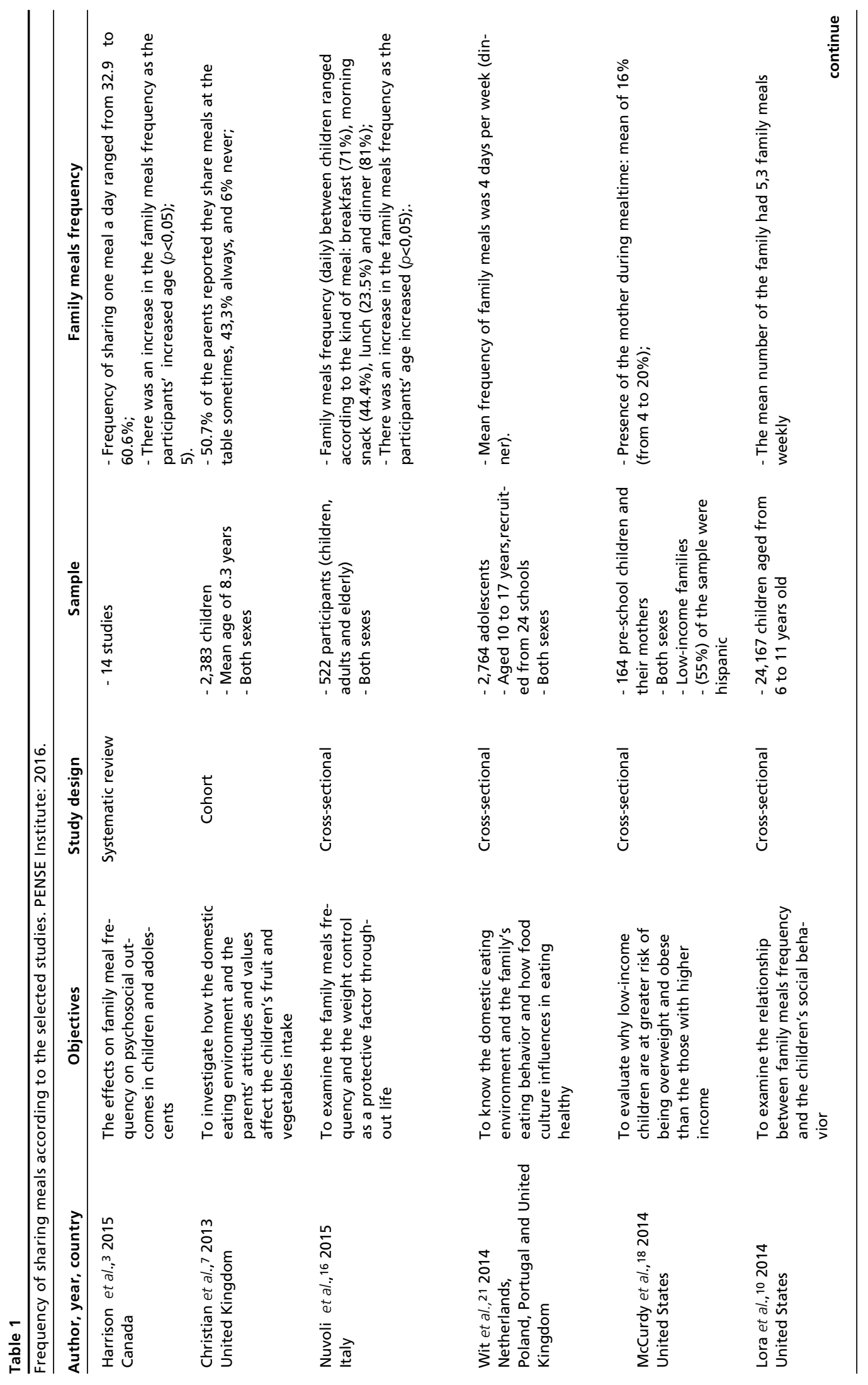




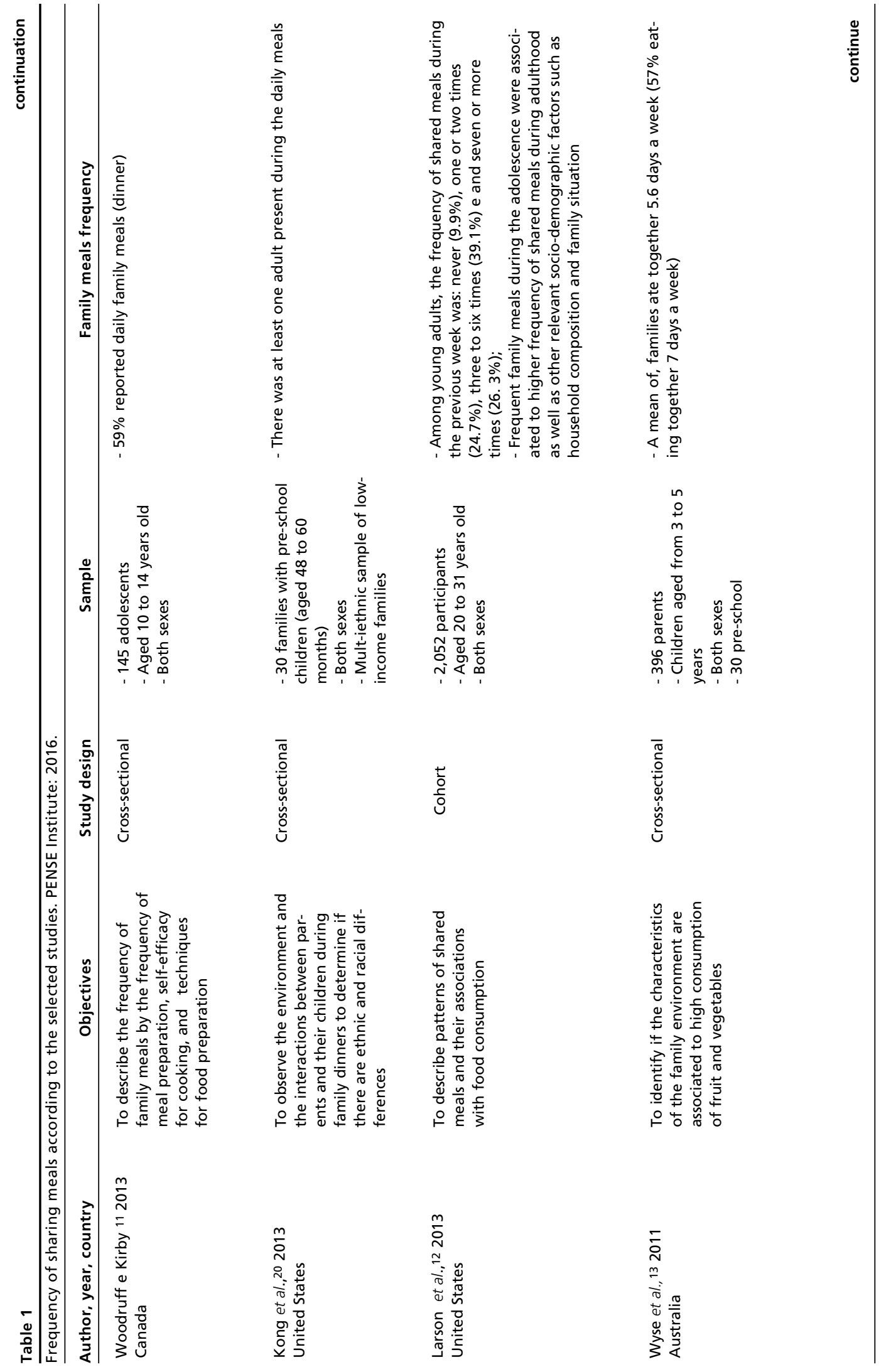



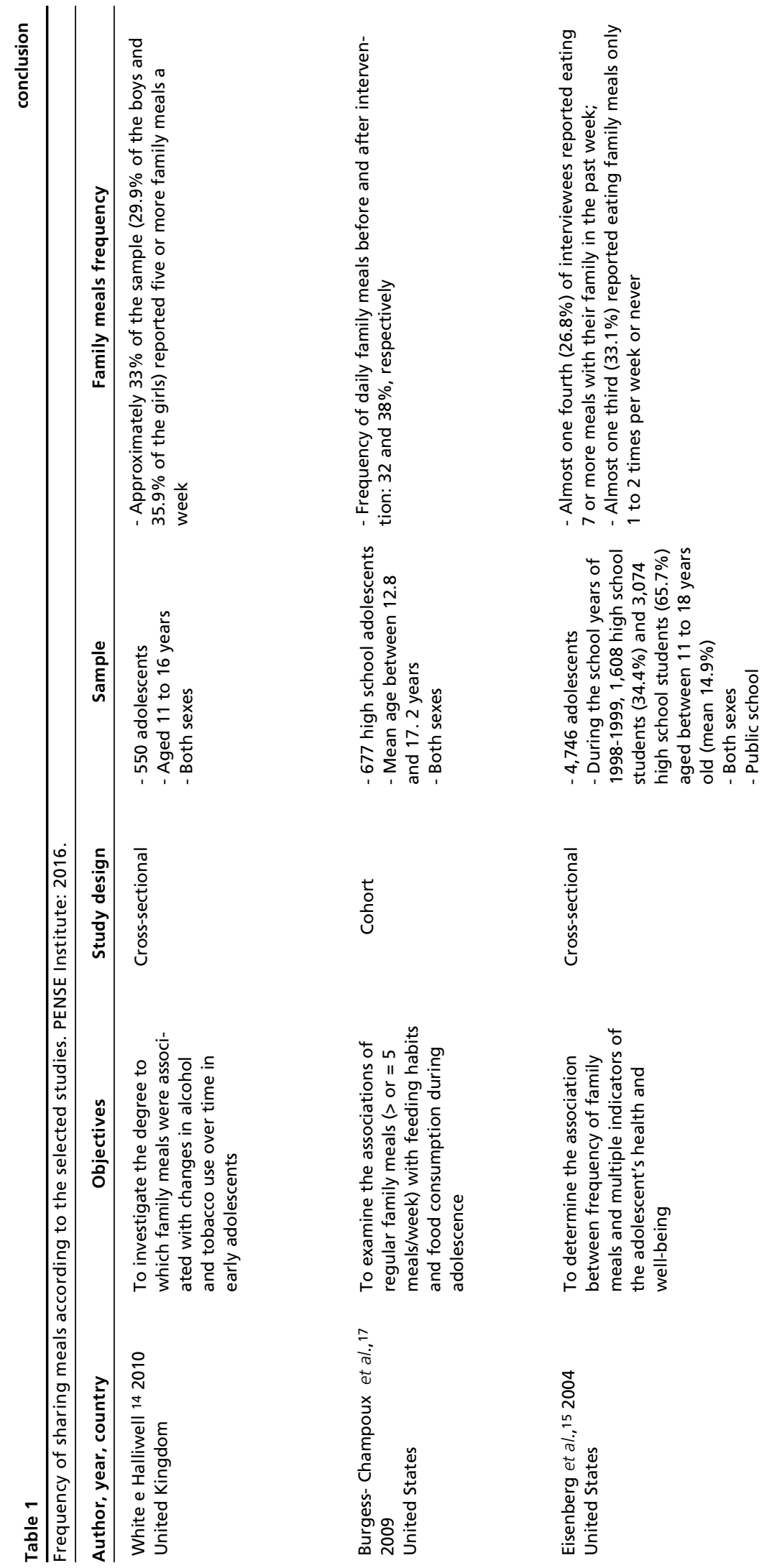

$\frac{\pi}{0}$

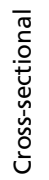
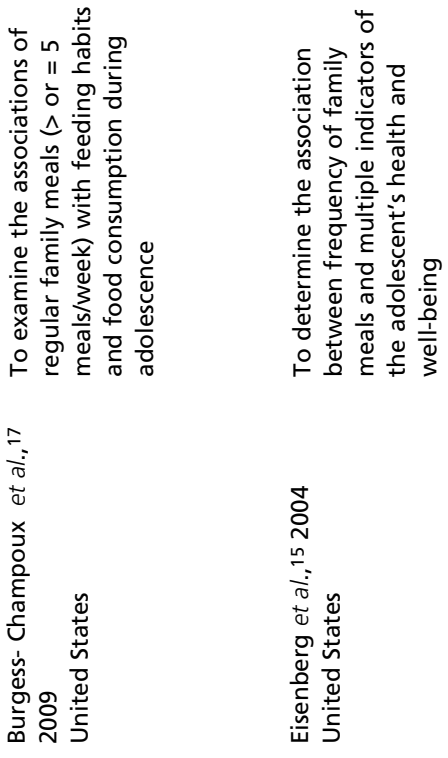
prevalence of at least one daily mealtime (regardless to which mealtime). In this study, the increase in maternal age and low schooling levels were associated to the reduction in the frequency of family mealtime. In the ERICA Study, 24 sampled with 74,589 adolescents aged 12 to 17 years old in 124 Brazilian cities, $68.0 \%$ reported "always or quiet often" having family meals. Similar in a study carried out in São Paulo, there was a higher prevalence of family mealtime among adolescents whose mothers had higher schooling levels, studied in private schools and live in the South and Midwest Regions. Therefore, the Brazilian data seem to be in agreement with the prevalence described in international literatures.

Although, there is no consensus on the number of times recommended for weekly family meals in providing health benefits, some authors indicate four or more mealtime per week is the ideal amount. 25 In an international meta-analysis of 17 studies, in a sample total of 182,836 children and adolescents, described the association of normal BMI and healthy eating habits occurred when the family mealtime was at least three times a week.26 Other studies suggest that at least one daily family meal was beneficially associated to eating disorders in older children,27,28 and the healthy eating habits and normal BMI in children and adolescents. ${ }^{29}$ In Brazil, the official recommendation from the Ministry of Health is that family mealtime should be as much as possible, without, however, an explicit recommendation of the ideal amount of food during the meals. 30

Among the reasons that could explain the lack of family meals, it can be described that the main factor is the current family routines, characterized by parents who arrive home late from work, and whose children eat earlier at school or with the caregivers. Even in the studies included in this review there are reports that dinner is the most shared meal with the family $(81 \%)$, followed by breakfast $(71 \%)$ and lunch $(23 \%), 16,11,17$ illustrating the possible logistical difficulties that accompany families' current work routines. The current family structure, which is increasingly composed by relationships which brings children together from other marital unions, or single-parent families can lead to overload the role in maintaining functions and also impacting on the frequency of family mealtime. ${ }^{31,32}$ Nuvoli et al. 16 and Harrison's et al. ${ }^{3}$ studies also show positive correlations between older children's age and the increased frequency of family mealtime, which could be explained by the adjustment of routines and schedules, tending to adult patterns as they get older.
In the Brazilian data mentioned previously, $22,23,24$ the prevalence of family mealtime is described only as 'lunch or dinner', which makes it difficult to compare which type of meal,. Anyway, a daily family mealtime (probably dinner) seems to be the only opportunity that the child and / or adolescent has to experience this moment of interacting with the family.

\section{Impact on the BMI and food quality}

Although the results of frequency are in accordance with the international literature, none of the Brazilian studies included in this study seek for associations between family meal frequency and markers on the participants' nutritional status, which limits the comparisons related to its impact on the BMI.

According to international data, continuous investments to promote this practice in family meals (especially in vulnerable socioeconomic groups) becomes extremely relevant when considering its benefits on maintaining a healthy BMI $18,20,19$ and the increase in the FV intake $7,8,12,17$ In Brazil, the current obesity rates are up to $15 \%$ and $20 \%$ among children and adolescents (respectively), the prevalence is among the highest rates in Latin America. ${ }^{33}$ Moreover, the data on the consumption of FV in the country indicate generalized inadequacy, with only about 30 to $50 \%$ of adequate intake among the young population. 34 Thus, the interventions that aim to reduce obesity, for example, can and should use strategies that include family mealtime.

A few available studies try to perform interventions aiming to promote family meals in Brazil, and there is no consensus in the literatures about the best method to be adopted. Kharofa et al. 35 propose a guide for such interventions with subsidize steps to guide appropriate practices at mealtime. Since family mealtime, is dependent of parental behavioral pattern and socioeconomic conditions, they become the main focus of the interventions and not the children.9,36 Although there is no methodological consensus, the interventions were already undertaken to meet these mentioned assumptions, as included in this review 8 and described by Adamson et al. 37 and Berge et al.,38 for example, described positive results in increasing the children's exposure to food and improving their relationship with the feeding processes after stimulating family mealtime, although they evidenced the parents' behavior and style during the meals there is an impact also on the difficulties of 
eating the most common food at childhood. Burgess et al., ${ }^{17}$ also described an increase of $6 \%$ in the frequency of family meals after the intervention period. Woodruff and Kurby 11 demonstrated that including children / adolescents in the cooking processes of meals may also be an effective strategy to increase the frequency of family meals $(\mathrm{OR}=1.15$; $p=0.02)$.

\section{Methodological limitations}

Despite the positive impact on the BMI and eating habits, most studies present some methodological limitations for analyzes and comparisons: they focus mainly on the prevalence of shared meals, -however, without describing manners and environment when the meal will occur; considering and analyzing the main meal differently (some authors consider lunch / dinner, while others consider breakfast); they are mainly based on school children and adolescents, with a scarce of work in early childhood (when eating patterns are formed); Do not thoroughly investigate reasons why families do not share meals as often as recommended; and do not discuss a possible consensus on the recommended number of weekly meals needed to provide health protection. 39 Such information is relevant to formulate the strategic action plans and their respective assessments.

\section{References}

1. Couch SC, Glanz K, Zhou C, Sallis JF, Saelens BE. Home food environment in relation to children's diet quality and weight status. J Acad Nutr Diet. 2014; 114 (10): 1569-79.

2. Pedersen S, Gronhoj A, Thogersen J. Following family or friends. Social norms in adolescent healthy eating. Appetite. 2015; 86: 54-60

3. Harrison ME, Norris ML, Obeid N, Fu M, Weinstangel H, Sampson M. Systematic review of the effects of family meal frequency on psychosocial outcomes in youth. Can Fam Physician. 2015 61: 96-106.

4. Fulkerson JA, Friend S, Flattum C, Horning M, Draxten M, Neumark-Sztainer D. Association with houseld food availability in United States multi-person households: National Health and Nutrition Examination Survey 2007-2010. Plos One. $2015 ; 2$ : 1-13.

5. Dwyer L, Oh A, Patrick H, Hennessy E. Promoting family meals: a review of existing interventions and opportunities for future research. Adolesc Health Med Ther. 2015; 6: 11531.

6. Newman SL, Tumin R, Andridge R, Anderson SE. Family Meal Frequency and Association with Household Food Availability in United States Multi-Person Households: National Health and Nutrition Examination Survey 2007 2010. Plos One. 2015; 12: e0144330.

7. Christian MS, Evans CE, Hancock N, Nykjaer C, Cade JE.
Further studies could focus on the interventions that facilitate the practice of family mealtime in groups that present greater barriers in home routines, such as both working parents, with extended working hours or lack of regular mealtimes, unbalanced family structure and inadequate eating habits. 5,40

\section{Conclusions}

The habit of having family meals was associated to maintain a normal BMI and good eating habits for children and adolescents at international level. The mean of shared meals in the studies was close to a daily meal, and among these factors that hamper this practice, highlight on the family routine and structure. Low socioeconomic condition and schooling levels were also associated to reduce the prevalence of shared meals. There is no consensus on the minimum recommendation of shared meals, but at least one daily meal is suggested; with adequacy of practicing this behavior. There is a gap of information that constitutes the opportunity to research and development new approaches that stimulate the practice of family mealtime in different populations.
Family meals can help children reach their 5 a day: a cross sectional survey of children's dietary intake from London primary schools. J Epidemiol Comm Health. 2013; 67 (4): 332-8.

8. Flattum C, Draxten M, Horning M, Fulkerson JA, Neumark-Sztainer D, Garwick A, Kubik MY, Story M. Home Plus: Program design and implementation of a family-focused, community based intervention to promote the frequency and healthfulness of family meals, reduce children's sedentary behavior, and prevent obesity. Int J Behav Nutri Phys Act. 2015; 12: 53.

9. Tumin R, Anderson SE. The epidemiology of damily meals among Ohio's adults. Public Health Nutr. 2015; 18: 147481.

10. Lora KR, Sisson SB, DeGrace BW, Morris AS. Frequency of family meals and 6-11-year-old children's social behaviors. J Fam Psychol. 2014; 28 (4): 577-82.

11. Woodruff SJ, Kirby AR. The associations among family meal frequency, food preparation frequency, self-efficacy for cooking, and food preparation techniques in children and adolescents. J Nutr Educ Behav. 2013; 45 (4): 296-303.

12. Larson N, Fulkerson J, Story M, Neumark-Sztainer D. Shared meals among young adults are associated with better diet quality and predicted by family meal patterns during adolescence. Public Health Nutr. 2013; 16 (5): 88393. 
13. Wyse R, Campbell E, Nathan N, Wolfenden L. Associations between characteristics of the home food environment and fruit and vegetable intake in preschool children: a crosssectional study. BMC Public Health. 2011; 11: 938.

14. White J, Halliwell E. Alcohol and tobacco use during adolescence: the importance of the family mealtime environment. J Health Psychol. 2010; 15 (4): 526-32.

15. Eisenberg ME, Olson RE, Neumark-Sztainer D, Story M, Bearinger LH. Correlations Between Family Meals and Psychosocial Well-being Among Adolescents. Arch Pediatr Adolesc Med. 2004; 158 (8): 792-6.

16. Nuvoli G. Family meal frequency, weight status and healthy management in children, young adults and seniors. A study in Sardinia, Italy. Appetite. 2015; 89: 160-6.

17. Burgess-Champoux TL, Larson N, Neumark-Sztainer D, Hannan PJ, Story M. Are family meal patterns associated with overall diet quality during the transition from early to middle adolescence? J Nutr Educ Behav. 2009; 41 (2): 7986.

18. McCurdy K, Gorman KS, Kisler T, Metallinos-Katsaras E. Associations between family food behaviors, materna depression, and child weight among low-income children. Appetite. 2014; 79: 97-105

19. Boles RE, Reiter-Purtill J, Zeller MH. Persistently obese youth: interactions between parenting styles and feeding practices with child temperament. Clin Pediatr (Phila) 2013; 52 (12): 1098-106.

20. Kong A, Jones BL, Fiese BH, Schiffer LA, Odoms-Young A, Kim Y, Bailey L, Fitzgibbon ML. Parent-child mealtime interactions in racially/ethnically diverse families with preschool-age children. Eat Behav. 2013; 14 (4): 451-5

21. de Wit JB, Stok FM, Smolenski DJ, de Ridder DD, de Vet E, Gaspar T, Johnson F, Nureeva L, Luszczynska A. Food culture in the home environment: family meal practices and values can support healthy eating and self-regulation in young people in four European countries. Appl Psychol Health Well Being. 2015; 7 (1): 22-40.

22. Instituto Brasileiro de Geografia e Estatística. Pesquisa Nacional de Saúde do Escolar (PeNSE). Rio de Janeiro: Ministério do planejamento, orçamento e gestão; 2013.

23. Sato PM, Lourenço BH, Trude ACB, Unsain RF, Pereira PR, Martins PA, Scagliusi FB. Family meals and practices among mothers in Santos, Brazil: a population-based study. Appetite. 2016; 103: 38-44.

24. Barufaldi LA, Abreu GA, Oliveira JS, Santos DF, Fujimori E, Vasconcelos SML, Vasconcelos FAG, Tavares BM. ERICA: prevalência de comportamentos alimentares saudáveis em adolescentes brasileiros. Rev Saúde Pública. 2016; 50 (supl 1): 6s

25. Eisenberg ME, Neumark-Sztainer D, Fulkerson JA, Story M. Family meals and substance use: Is there a long-term protective association? J Adolesc Health. 2008; 43: 151-6.

26. Hammons AJ, Fiese H. Is Frequency of Shared Family Meals Related to the Nutritional Health of Children and Adolescents? Pediatrics. 2011; 127 (6): e1565-74.

Received on July 14, 2016

Final version presented on May 25, 2017

Approved on June 22, 2017
27. Fulkerson JA, Story M, Mellin A, Leffert N, NeumarkSztainer D, French SA. Family dinner meal frequency and adolescent development: relationships with developmental assets and high-risk behaviors. J Adolesc Health. 2006; 39(3): 337-45.

28. Neumark-Sztainer D, Wall M, Story M, Fulkerson JA. Are family meal patterns associated with disordered eating behaviors among adolescents? J Adolesc Health. 2004; 35 (5): 350-9.

29. Woodruff SJ, Hanning RM. Associations between family dinner frequency and specific food behaviors among grade six, seven, and eight students from Ontario and Nova Scotia. J Adolesc Health. 2009; 44 (5): 431-6.

30. Brasil. Ministério da Saúde. Guia Alimentar para população Brasileira. 2 ed. Brasília: Secretaria de atenção à saúde. Departamento de atenção básica; 2014.

31. Horta RL, Horta BL, Pinheiro RT. Drogas: famílias que protegem e que expõem adolescentes ao risco. J Bras Psiquiatr. 2006; 55 (4): 268-72.

32. IBGE (Instituto Brasileiro de Geografia e Estatística). Pesquina Nacional de Amostra de Domicílios (PNAD). Rio de Janeiro; 2009.

33. RNPI (Rede Nacional Primeira Infância). Obesidade na primeira infância. Projeto observatório nacional da primeira infância. FOrtaleza/CE: Secretaria Executiva da RNPI biênio 2013/2014, Instituto da Infância (IFAN); 2014.

34. Machado RHV, Feferbaum R, Leone C. Consumo de frutas no Brasil e prevalência de obesidade. J Human Growth Dev. 2016; 26 (2): 243-52.

35. Kharofa Y, Kalkwarf J, Khoury JC, Copeland KA. Are Mealtime Best Practice Guidelines for Child Care Centers Associated with Energy, Vegetable, and Fruit Intake? Childhood obesity. 2016; 12 (1): 52-8.

36. Rhee KE, Dickstein S, Jelalian E, Boutelle K, Seifer R, Wing R. Development of the general parenting observational scale to assess parenting during family meals. Int $\mathrm{J}$ Behav Nutr Phys Act. 2015; 12: 49-64.

37. Adamson M, Morawska A, Wigginton B. Mealtime duration in problem and non-problem eaters. Appetite. 2015; 84: 228-34

38. Berge JM, Wall M, Neumark-Sztainer D, Larson N, Story M. Parenting style and family meals: cross-sectional and 5year longitudinal associations. J Am Diet Assoc. 2010; 110 (7): $1036-42$.

39. Skafida V. The family meal panacea: exploring how diferent aspects of family meal occurrence, meal habits and meal enjoyment relate to young children's diets. Sociol Health Illn. 2013; 35 (6): 906-23.

40. Fulkerson JA, Larson N, Horning M, Neumark-Sztainer D. A review of associations between family or shared meals frequency and dietary and weight status outcomes across the lifespan. J Nutr Educ Behav. 2014; 46 (1): 2-19. 